\title{
Acerca del Centro de Estudios en Derecho Informático
}

\author{
PROF. ALEX PESSÓ STOULMAN \\ Coordinador Académico \\ Centro de Estudios en Derecho Informático \\ Facultad de Derecho, Universidad de Chile
}

Este es un momento muy especial para nuestro Centro de Estudios en Derecho Informático, creado originalmente en octubre de 1988 como Centro de Computación e Informática Jurídica (CCIJ), y que constituyó el primer intento de una Facultad de Derecho latinoamericana de estudiar, analizar y reflexionar acerca de la incorporación de las tecnologías informáticas a entornos jurídicos.

Sin embargo, la tecnología es un ámbito en constante modificación. La celeridad en la transformación de las telecomunicaciones, ya sea en su forma de radiofonía, telefonía, televisión o transmisión de datos, ha exigido a nuestro Centro desarrollar la capacidad de adaptarse a la innovación permanente, asegurando la investigación y docencia en estas áreas del derecho, a través de iniciativas que han permitido analizar la nueva legislación vigente y, por sobre todo, contar ahora con un mecanismo de difusión y publicación que cumpla con los más altos estándares internacionales.

Por lo anterior es un privilegio dar inicio a la publicación de la Revista Chilena de Derecho y Tecnología, publicación semestral del Centro de Estudios en Derecho Informático de la Facultad de Derecho de la Universidad de Chile, continuadora de la Revista Chilena de Derecho Informático, y que tiene por objetivo difundir en la comunidad jurídica nacional, regional e internacional, el conocimiento científico relevante y 
necesario para analizar y comprender los alcances y efectos que el desarrollo tecnológico y cultural han producido en la sociedad, especialmente su impacto en las ciencias jurídicas y sociales.

Las principales áreas temáticas de la revista versarán sobre propiedad intelectual e industrial, incluyendo los derechos de autor, las marcas comerciales, los nombres de dominio, las indicaciones geográficas, los conocimientos tradicionales y los recursos genéticos. Sus páginas también darán cabida a estudios doctrinales y jurisprudenciales sobre el estatuto jurídico de la innovación, la contratación electrónica, tanto pública como privada, la protección de la vida privada y de los datos personales, los delitos informáticos, las telecomunicaciones, incluyendo, por cierto, a Internet y su emergente regulación: la responsabilidad de los ISP y la neutralidad en la red, las regulaciones sobre sociedad de la información, nanotecnologías, gobierno electrónico y televisión digital, incorporando también las discusiones sobre derechos culturales, industrias culturales y del entretenimiento, diversidad cultural, y, en general, sobre todos los ámbitos de relación que puedan existir entre las tecnologías, la sociedad y el derecho.

El lanzamiento de esta nueva publicación se enmarca en un contexto de cambio institucional de nuestro Centro, en el que recientemente se ha modificado el Magíster en Derecho de la Informática y las Telecomunicaciones, adaptando el grado académico al de «Magíster en Derecho y Nuevas Tecnologías», y adecuando la normativa a un escenario flexible y de permanentes modificaciones.

Además se han integrado al Centro nuevos investigadores, a través del respectivo concurso público, como es el caso de los profesores señores Claudio Magliona Markovicth, Salvador Millaleo Hernández, Rodrigo Moya García y quien suscribe, que se integran al equipo conformado además por los profesores señores Alberto Cerda Silva, Carolina Cruzat Vega y Daniel Álvarez Valenzuela, quienes desde su vasta experiencia en estos ámbito del derecho ciertamente consolidarán el proceso de transformación institucional, asegurando contar a la Facultad de Derecho de la Universidad de Chile con un centro moderno y actualizado que esperamos sea un faro a nivel nacional e internacional.

Cabe destacar el esfuerzo del editor general de la nueva Revista Chilena de Derecho y Tecnología, profesor Daniel Álvarez Valenzuela, quien ha logrado realizar todas las acciones necesarias para volver a proponer 
a la comunidad académica, nacional e internacional, una obra que seguro será reconocida y valorada por su calidad, pertinencia, pluralismo y relevancia.

Finalmente quisiera agradecer el permanente apoyo del señor decano de la Facultad de Derecho, profesor Roberto Nahum Anuch, quien ha sido un actor fundamental en la modernización del Centro de Estudios en Derecho Informático y, por cierto, en la publicación de la nueva $R e$ vista Chilena de Derecho y Tecnología. 
